\title{
Integrated and Seamless Services for Active Aging, a Model for Zhuhai
}

\author{
H. C. J. Wong, Y. F. Ng, X. L. Yuan \\ Beijing Normal University - Hong Kong Baptist University United International College, Zhuhai, China \\ Email: johnstonhuang@uic.edu.hk
}

Received July 2014

\begin{abstract}
The Aging Tsunami as it is often quoted to describe the worrying situations of rapidly aging in China has not met with detail planning in facilities upgrade and careful consideration in service models. Broad brushed central policies categorizes services into home care, community care and institutional care and set policy goals at 90-6-4, representing the percentage of older people in receiving respective care. This leaves local officials helpless on how these ideals can be actualized. Some cities have inclined to build huge older people homes and pour resources into institutional care, forgetting the need for older people to be connected with the society. This paper reviews the historical developments of older people services in Hong Kong and recommends an integrative model of social work services connecting institutional, community and home care into a seamless network. The city of Zhuhai will be presented as a perfect experimental city on how its existing facilities can be converted and developed according to the model. Survey on the situations of the 16 public older people homes will be used to illustrate the potentials of an integrative model.
\end{abstract}

\section{Keywords}

Integrated Care, Active Aging, Seamless Care, Social Innovations

\section{China's Plan to Combat Rapid Aging}

The "China Social Services Network Development Plan (2011-2015)" (hereinafter referred to as the Plan) proposed by 2015 to "establish a basic infrastructure which is well organized, appropriately scaled, smoothly operated, quality serviced, properly supervised and sustainable social care service system for the older people" [1].

According to the Plan, in 2015 China's elderly population will reach 221 million or $16 \%$ of the total population; in 2020 it reaches 243 million and 18\%. Currently, including semi-urban and rural areas, the number of older people who are not able to take of themselves because of various disabilities and dis-functioning is 33 million, accounting for $19 \%$ of the total elderly population. It means that one in five of the older people need certain degree of assisted care. The ratio will rise as the total number of older people continues to increase.

The Plan further explains that the social service system for older people mainly consists of three components: home care, community care and institutional care [2]. 
Home care services cover daily living assistance such as bathing and personal cleansing, housekeeping services, meal delivery, home rehabilitation care, home basic health care and psychological comforting, all assuming services to the door. Home innovation to allow for barrier free environment, provision of walking aids and special subsidy to those who cannot take care of themselves are also recommended by the Plan as supplementary home care measures.

Community care services is an important support for home care services.

The Plan clearly states that community care services should include day and temporary care services and home help services targeted at those families who have no one to take care of the older people during day time. In the city, day care facilities should be part of the development of community facilities. In the countryside, the Plan particularly stated that we should fully utilize the capacities of the Village Old Age Home. Day care facilities should be incorporated into existing old age homes and enhance its link with the community. Eventually these old homes can become District Older People Service Centre, with home help and community health care team serving all the older people living with or without family members in the district. A comprehensive service network can be developed so to speak. Developing mutual help among older people is also encouraged.

Institutional care is like the tertiary level of care, borrowing a health care term.

Institutional care should focus on facilities building. Elderly homes should cater mainly for those who are unable to take care of themselves. Nursing care should therefore be most needed and rank high on the priority.

Functions of Nursing homes should include the following:

1. To provide Daily Living Care to older people residents;

2. To provide Rehabilitative Nursing to residents as well as older people living in neighboring areas;

3. To provide Emergency Rescue to older people living in the areas; and

4. To reach out to the community and develop a network of services to older people.

\section{Inadequacies of Existing Services}

However the Plan also pointed out that China's care for the elderly is facing tremendous problems notably in the following aspects:

1. Lack of overall planning, integration and continuity of services;

2. Serious shortage of beds with nursing care;

3. Most existing old age homes have very poor physical facilities, not designed for comprehensive services;

4. Disparities in regional provisions of facilities, sharp differences between the rural and urban areas;

5. Inadequate government financial support and limited private investment to construct necessary facilities;

6. Lack of professional service staff;

7. Central policies in favor of older people services are not implemented locally;

8. Professional standards and self discipline for older people services have yet to be regulated and improved.

To create a new service model and to overcome the above difficulties, in fact, as early as 2009 the Ministry of Civil Affairs together with the Development and Reform Commission have selected Heilongjiang, Jiangsu, Hubei, Chongqing and Gansu five provinces to carry experimental projects [3]. The project differentiates services for older people into two categories, namely "Basic Services Provisions" and "Supplementary and supportive Services Provisions". Basic Provisions are universal benefits to enhance healthy aging for all older people normally provided by the Government. The latter refers to those services and practices provided by government as well as the market. However non-profit organization should play a major role in such supplementary efforts that might bring higher quality of life to older people [4].

In these pilot projects, five principles to develop a future older people services network are suggested [3]:

1. Comprehensiveness, providing a full range of services catering to the needs of different stages of aging, say below 75, 75 to 89, and above 90;

2. Varieties, different options to services to satisfy individual preferences;

3. Continuity, services should be sustainable and free from interruption;

4. Effectiveness, able to alleviate burdens to the family, government and society by providing a comfortable living environment to the older people and enhancing their quality of life;

5. Economical, as China has a huge older people population the government while recognizing the urgency to provide services and facilities, emphasizes that services must be affordable by the society. 
These principles are still very broad and left the city or community administrators very confused about what should be done. This paper will try to describe a delivery model of services to older people based not only on the successes but also on the failures of the Hong Kong experience.

\section{Development of Elderly Services in Hong Kong}

Nelson Chow (Chow, 1987) describes the four stages of Elderly care in Hong Kong as follows [5]:

1) In the first phase, elderly care depended entirely on the families, relatives and friends. Care for parents were considered as the responsibilities of the next generations;

2) In the second stage, alternative form of care provided by private business or charitable organizations emerged;

3) In the third stage, public social services for older people were generally considered as a necessary complement to family support. The concept of "Open Care" is widely accepted with the introduction of "community-based services" to supplement institutional care; and in

4) The fourth stage, a comprehensive approach or holistic care combining financial assistance with professional services is developed and supported by the government.

The City of Tsingdao in 2004 published a report on a study tour to Hong Kong and Macao [6], commended the Hong Kong care for older people as:

1) Showing high respect to the value and dignity of the older people. Hong Kong encourage healthy elderly to continue to participate in society and those who are more fragile to maintain their highest level of self-care skills. Independence in daily life is considered important to enhance self-esteem and a sense of control over the environment for the older people;

2) Laying strong emphasis on personalized service and case work. Issues facing each elderly, psychological, physical, social and economic, are individualized, so are the solutions to solve such problems;

3) Trying to provide continuum of care. As residents of old age home grow older their physical functioning weaken. The Hong Kong service sector is trying hard to serve older people in the same service unit by improving the nursing facilities and manpower of the homes. Therefore older people with low, medium and high levels of nursing needs can be served in a comprehensive home;

4) Understanding the need for psychological treatment and rehabilitative training. As the number of high age older people increases the need to prevent mental deficiencies also increases; and

5) Concerning not only the older people clients but also their carers. Supportive services and counseling to the family members of the older people are considered necessary. Centers for carers are established in the community level (City of Tsingdao, 2004).

In Hong Kong comprehensive services or the Holistic Care Model is recognized as the best mode to provide services for the older people. Physical, social and psychological needs of older people are inter-correlated and meet these requirements in maximum terms means that we have to develop service in an integrated manner [7]. For Hong Kong at least if public policy is concerned the issue is no longer whether government intervention is necessary but to what extent the government should undertake whenever families and communities fail to care of the older people [7].

\section{Undesirability and Inadequacies the Hong Kong System}

Holistic care model with its universal nature, though no one disagrees, may not be welcomed in many Asian countries. Truly high degree of industrialization, urbanization and mobility in East Asia put many families in very difficult situations when it comes to taking care of older people. Truly public support is required to provide older people basic care. Yet Asian governments are inclined to provide the social minimum. High social welfare through high taxation may jeopardize the economy, dominates the political thinking in this part of the world. Therefore in some countries elderly care are equated with care by the family, as in the first stage of development in Hong Kong.

It is therefore not surprising to have heard some worries about "whether the implementation of such a comprehensive services for older people will indeed contribute to the disintegration of the family" [8]. Of course Korea cannot resist the demand for more old age homes from its voters at the end.

On the other hand it is doubtful whether the holistic model works well for the older people. Traditional Chi- 
nese philosophy of filial piety favors the notion of "Care in the Community", highlighting the importance of communal life for the elderly. However supplementary services provided to families to keep older people in the community are far from adequate in many places including Hong Kong. Currently in Hong Kong the systems of formal care and informal care seem are serving different target groups, the former concentrating on single elderly while the latter on those who have family members. It is obvious that the need for institutional care continue to rise and supply fall far short of demand. As a result many older people are left in very poor living conditions and low level of care [9].

Major problems of Hong Kong system can be summarized as follows [10]:

1) overly high ratio of older people lived in institutions instead of living in the community;

2) over-reliance on public funds;

3) quality of care in different homes varies sharply;

4) universal community care services may over-stipulate demand.

Funding of the Hong Kong model derives mainly from governmental revenues either directly through purchasing services from non-governmental organizations or indirectly through the public assistance to the older people who pay to private operators of old age homes.

In 2009, Hong Kong government provided for 21,000 subsidized residential places for older people of which 14,391 places were offered by NGOs' The government also purchased services from qualified private homes for the remaining 6614 places. The ratio of beds provided by private operators in fact is as high as $70 \%$. Since most users of private homes are the recipients of Comprehensive Social Security Assistance (CSSA) Scheme, the government is actually indirectly funding the private sector.

For community services there were only 7089 places. The expenditure for institutional care amounted to HK\$2549 million whereas expenditure for community care services was only HK\$381 million. Inadequate community facilities further pushed people to opt for institutional care. In 2009 research found that $6.8 \%$ of older people in fact preferred residential care [11].

NGOs only received $80 \%$ subsidy for older people's community services. Services are non-mean tested and provided on grounds of physical and social needs assessed by the service providers. This may lead to overlapping of services and waste of resources as agencies compete in the same community [10].

For future development of older people's services, Hong Kong should consider the following directions [11]:

1) Providing Integrated services across different age ranges of older people, even integrating older people with children, youth and family services;

2) Attracting through financial subsidy more non-profit organizations to provide services to older people;

3) Supporting the home carers of the older people through better community healthcare services and counseling services;

4) Expanding mental health services to older people who are experiencing more mental deficiencies due to aging;

5) Tightening the monitoring of services provided by private operators to ensure basic quality of life for their older people residents.

Notably, in Hong Kong formal care and informal care instead of complementing each other cover only the most needy. This may be the reason why the Chinese authorities choose to adopt the concept of "Basic and Supplementary Care" instead of "Formal and Informal Care" in their pilot projects.

China, having similar economic considerations like other Asian countries, hopes that the market can become a collaborative partner of the State. Unfortunately market for older people's services is not yet there. Lack of tax or land incentives, foreign private investors can only targeted at those who can afford, the niche market so to speak. NGOs and charitable funds, on the other hand are still emerging. Few of them have the finance and expertise to operate old age homes. If China has to find a mix mode in financing its services for older people, from where can money be raised? How should money be directed? How to draw the line between public sector and private market? What are the roles of NGOs and social enterprises? All these are interesting questions to be answered in the mapping of a new Service Delivery Model for Older People of China.

\section{Social Innovations for Zhuhai and Other Mid-Sized Cities}

The overall goal for the city of Zhuhai by 2015 is the magic number of: "9064" referring to $90 \%$ of the older 
people will be taken care of by the family, $6 \%$ by community and $4 \%$ by institution [12]. This is a higher than national standards which suggested on "9073". However the statistical data may not reflect what kind of care older people are actually enjoying in different categories of family, community and institutional care.

As mentioned earlier Hong Kong advocated for the Holistic Care Model of Older People. However it is limited by never sufficient public resources. Service gaps are evident and many many older people, $70 \%$ according to the Elderly Commission Report 2009, are living in privately run homes with very poor conditions. Seamless Care for All is now advocated by many experts in elderly care in Hong Kong.

Comparing with Hong Kong, Zhuhai, like many other mid sized cities in China, is not without its advantages and strengths. Physically, land for facilities and space in homes are more readily. Socially, filial piety is still upheld and family relations are more intact. In terms of work culture people are more relaxed and enjoyed a five days working week. People will be more available to spend time with their old age parents living together, alone or in institutions. Politically and culturally volunteer services is encouraged and young students always visit elderly homes.

To plan older people's services for Zhuhai or similar cities in China, a Seamless Service Model combining Basic and Supplementary Care is proposed. Non profit charitable organizations should play an important role in this network taking the form of social enterprises. If the infrastructure is adopted by the authorities and supported by the local communities, Zhuhai will become the Florida of China.

Currently there are 16 public old age homes in the Zhuhai. They were designed and built as hostels for single older people without family. It is assumed that they are still capable to take care of themselves. If physical heath of residents deteriorates a personal worker will be hired to look after them individually. No training is required or provided to the personal worker. Similar situations apply to other cities in Guangdong though some areas have opened up these old age homes to older people with families with a monthly charge. In a few leading cities simple training are offered to care workers of old age home.

For Zhuha, it is recommended that existing old age homes should be converted to provide nursing care, to fulfill the policy goal of $4 \%$ institutional care targeted at those older people who can no longer lived on their own without nursing care. These old age homes should be converted into "Comprehensive Nursing Home" as stipulated in the Plan.

To clarify various terms "Older People Hostel" refer to those dormitory of "Independent Living" where residents are expected to take of their own living entirely. "Older People Housing” refer to those facilities in which residents are provided with food, laundry, simple health care and cleanliness services. It is a type of "Assisted Living”. Finally “Older People Nursing Housing” refer to facilities providing high level of nursing care to those who partially or totally unable to take care of themselves; "Cared Living" as it may be called. A Comprehensive Nursing Home however should provide all three Housing types and Living styles.

The Comprehensive Nursing Home will become the focal point of older people services in the district, with its social work teams reaching out to communities and families. A Day care center with rehabilitative functions will be incorporated in each of this comprehensive home integrating social and medical services.

On August 16, 2013, Premier Li Keqiang chairing a State Council executive meeting, instructed that Older People care should be integrated with Healthcare services in all aspects, supported by social security provisions as well as health insurance [13]. It is predictable that community medicine and nursing provisions will be expanded and reachable for older people living under family care.

Furthermore, at the community or village level, it is suggested to set up "community kitchen" to provide dietary food for older people. Home help services can also be organized and supervised by resident or village committees. Community workers now employed by resident or village committees can be trained up to form "community social work teams" to organize meaningful activities for healthy older people in the district. Social workers reaching out from the Comprehensive Nursing Homes can collaborate with these community social workers and form the platform of a connected network of care. The service network bridges the gaps and form the framework of Seamless Services.

All these services should be managed by a non-profit organization, including social work services, health services, rehabilitation services and daily living support services such as food catering and home help (See Table 1):

To summarize, city leaders must first conceptualize the proper model of services provided to older people before we can tackle other problems like finance and manpower planning. This model will fully utilize existing 
Table 1. Levels of seamless and integrated care.

Geriatric Hospital

Comprehensive Nursing Home

(providing Cared Living, Assisted Living and Independent Living facilities, plus a Day Care Center, plus the District HQ of Social Work Team for Older People)

District Health Station

(providing medical clinic services, rehabilitation services, family planning services plus a Social and Activities Center for Older People)

Resident and Village Committees

(providing regular and festive activities for the elderly, organizing and managing home help services, plus community kitchen)

Family Care

resources and publicly owned facilities. Upgrading and renovation costs are comparatively economical. The Model also confirms the Welfare Nature of major institutional care. Private care are directed to the niche market and high end and luxurious living which appeals to a small sector of older people. Public homes operated by non profit organization attracts support from charitable organizations and funds. In this way it can also tap community resources and encourage altruism within the next generation. Integrating services for older people with services for children, youth and family form another coherent structure for total social integration and harmony for the society.

\section{References}

[1] Chinese State Council (2011) 12th Chinese National Social and Development Plan, March 2011. http://www.gov.cn/2011lh/content 1825838.htm

[2] Chinese State Council (2011) Social Plan for Service Systems for Older People (2011-2015), SCS [2011] No. 60. http://shfl.mca.gov.cn/article/tzgg/201204/20120400299795.shtml

[3] Sun, Y.Q. (2010) Expert Meeting on Future Development of Elderly Homes, Development and Reform Commission, Ministry of Civil Affairs, China Civil Affairs, 2010, 06.

[4] Chinese Development and Reform Commission \& Chinese Ministry of Health, 2010. Community Health Service Plan, Chinese Community Doctors, 2010-03.

[5] Chow (2007) Aging and the Family in Hong Kong. International Journal of Sociology of the Family, 33, Aging in Asia (Spring 2007), 145-155.

[6] Zhang, S.B. (2009) Experience and Implications of Elderly Services in Hong Kong-Report of Hong Kong and Macao Study Tour on Aging. http://tclgb.taicang.gov.cn/art/2009/6/19/art 5261 48134.html

[7] Chow, Y.X. and Zhao, R. (2010) Elderly Chinese and Western Support System—Comprehensive Care Model Pursued in Hong Kong. Population and Development, Beijing.

[8] Korean Ministry of Health and Social Affairs (1979) Annual Report of Korean Ministry of Health and Social Affairs, 1979:46.

[9] Little, V.C. (1979) Open Care of the Aging: Alternative Approaches. Aging, 301, 10-23.

[10] Ding, H. (2007) Integration and Diversification—Reflection on Latest Development of Older People Services in Hong Kong. Northwest Population, 2007, 01.

[11] Hong Kong Elderly Commission (2009) Consultancy Study on Elderly Residential Care Services. University of Hong Kong, 2009-12.

[12] Zhuhai Municipal People’s Government Office (2013) On Accelerating the Development of the Implementation of Social Services for Older People. Zhuhai Government Office, 2013, Notice No. 1. http://zwgk.gd.gov.cn/006988427/201303/t20130304_368679.html

[13] Chinese State Council (2013) Accelerating Development of Services to Older People through Social Participation. China News, August 16, 2013. http://www.chinanews.com/gn/2013/08-16/5173338.shtml 